\title{
An intercomparison of burnt area estimates derived from key operational products: the Greek wildland fires of 2005-2007
}

\author{
D. P. Kalivas ${ }^{1}$, G. P. Petropoulos ${ }^{2}$, I. M. Athanasiou ${ }^{1}$, and V. J. Kollias ${ }^{1}$ \\ ${ }^{1}$ Department of Natural Resources Development and Agricultural Engineering, Agricultural University of Athens, \\ Iera Odos 75, 11855 Athens, Greece \\ ${ }^{2}$ Institute of Geography \& Earth Sciences, University of Aberystwyth, Old College, King Street, SY23 2DB Aberystwyth, \\ Wales, UK
}

Correspondence to: D. P. Kalivas (kalivas@aua.gr)

Received: 30 December 2012 - Revised: 23 April 2013 - Accepted: 2 May 2013 - Published: 13 June 2013

\begin{abstract}
With the support of new technologies such as of remote sensing, today's societies have been able to map and analyse wildland fires at large observational scales. With regards to burnt area mapping in particular, two of the most widely used operational products are offered today by the United States National Aeronautics and Space Administration (NASA) and the European Forest Fires Information System (EFFIS) of the European Commission. In this study, a rigorous intercomparison of the burnt area estimates derived by these two products is performed in a geographical information system (GIS) environment for the Greek fires that occurred from 2005 to 2007. For the same temporal interval, the relationships of the burnt area estimates by each product are examined with respect to land use/cover and elevation derived from CORINE 2000 and the ASTER global digital elevation model (GDEM), respectively. Generally, noticeable differences were found in the burnt area estimates by the two products both spatially and in absolute numbers. The main findings are described and the differences in the burnt area estimates between the two operational datasets are discussed. The lack of precise agreement between the two products which was found does not necessarily mean that one or the other product is inaccurate. Rather, it underlines the requirement for their calibration and validation using highresolution remote sensing data in future studies. Our work not only builds upon a series of analogous studies evaluating the accuracy of the same or similar operational products worldwide, but also contributes towards the development of standardised validation methodologies required in objectively evaluating such datasets.
\end{abstract}

\section{Introduction}

Wildland fires cause an increasing amount of damage both to environmental systems and infrastructure worldwide, and form one of the most widespread ecological disturbances of natural ecosystems (FAO, 2001). Although in the short term fires occurrence can be regarded as an irregular disturbance, at wider temporal observation intervals it may attain a more regular character (Farina, 2000; Di Pasquale et al., 2004). In the Mediterranean region in particular, fire is a natural and recurrent element, as $90 \%$ of all wildland fires take place every year in those areas (Rosa et al., 2008). The high frequency of fires in the Mediterranean has been closely linked to the climatic conditions that dominate in these areas, characterised by prolonged drought periods generating favourable conditions for fire outbreaks (Cuomo et al., 2001; Zammit et al., 2006). In addition, the climate change, along with the effects of various anthropogenic activities, further increase the risk of fire occurrence and thus the damage caused to both nature and economy (Boboulos and Purvis, 2009). The wildland fire occurrence in those areas has a major impact on the economy of affected countries, influencing also the broader European Community through the destruction incurred in marketable assets (Sifakis et al., 2011). This is why being able to acquire information on past fire events and map the burning from wildfire has been underlined as a matter of key importance to both environmental scientists and policy makers (Rong et al., 2004; Kasischke et al., 1995; Giglio et al., 2006).

The technological advancements in the past three decades or so have made it possible to monitor the landscape change caused by wildland fires from space by using Earth 
Observation (EO) data. Over the last few decades substantial progress has been made in spaceborne industry, including the development of various satellite systems. Those have allowed satellite images to be acquired at different spatial and spectral resolutions, providing data important in wildland fire studies. Different types of remote sensing data have been exploited for more than $20 \mathrm{yr}$ in performing various fire analysis investigations, including mapping the extent of burnt areas (e.g. Trigg and Roy, 2007; Roy and Boschetti, 2009; Petropoulos et al., 2010).

EO-based operational products related to fire analysis have also been developed and are offered today in the form of regional-scale products by international space agencies at no cost and at a wide range of spatial resolutions (Lentile et al., 2006). Such products have proved to be generally in high demand from research groups and communities interested in modelling the carbon cycle, understanding the relationships between fire regime and climate as well as atmospheric emissions and pollution resulting from fires, and the impact of vegetation burning on land cover change (Patra et al., 2005; Jupp et al., 2006). The availability of operational products related to burnt areas in particular can additionally provide important information on land cover change related to ecology and biodiversity, and contribute significantly to better understanding post-fire recovery of an affected area (Rong et al., 2004).

Two of the most widely used EO-based monitoring systems currently providing operationally fire analysis products are operated by the European Information System for Forest Fires (EFFIS, http://effis.jrc.ec.europa.eu/) and NASA (http: $/ /$ modis-fire.umd.edu/index.html). EFFIS (European Commission, 2010) is a meteorological and satellite-based fire mapping system developed by the European Commission's (EC) Joint Research Centre (JRC). It has been in operation since 1997 and its main role is to provide EC member states during the European fire season, from May to October, with daily fire danger warnings and subsequent damage assessments. On the other hand, NASA distributes a suite of fire analysis products based on the Moderate-Resolution Imaging Spectroradiometer (MODIS) sensor (Justice et al., 2002). MODIS fire analysis products have been in operation on a global scale since 1999. Today both the above systems provide operationally different remote-sensing-based fire analysis products, including a product focused on burnt area estimation.

Development of those operational burnt area products has been based on well-established methodologies, and their use has been extensively demonstrated for mapping the extent of burnt areas in different geographical regions (Li et al., 2000; Hoelzemann et al., 2004; Simon et al., 2004; Vivchar, 2011). Yet, to our knowledge, very few validation studies have established the accuracy at which estimates of burnt area by those products is provided. Such studies have been based primarily on performing either direct comparisons with higherresolution data or intercomparisons between the different datasets (Boschetti et al., 2004, 2008; Silva et al., 2005; Roy et al., 2008; Roy and Boschetti, 2009; Sedano et al., 2012), despite the fact that it is indispensable to objectively characterise the accuracy of global datasets and their limitations for providing a measure of quality of a dataset, and for understanding their errors and the potential implications in different applications (Silva et al., 2005). What is more, policy and management requests of satellite products for different types of applications place a high priority on providing statements about their accuracy (Morisette et al., 2006). In the case of fire analysis products from moderate-resolution sensors, such as those provided by NASA and EFFIS, different users would be interested in knowing the accuracy of the products (Roy et al., 2006; Trigg and Roy, 2007; Roy and Boschetti, 2009).

Furthermore, performing intercomparison studies of the burnt area estimates between operational products is also regarded as a necessary step towards an objective verification of their accuracy. Indeed, this can provide an indication of gross dissimilarities and, potentially, insights into the causes for the differences observed (Roy and Boschetti, 2009). Understandably, such studies, performed in regions like the Mediterranean, can be of particular significance, given the very high occurrence of fires in those areas and their relevance to other co-occurring phenomena such as land degradation and desertification (Castillejo-González et al., 2009).

In this context, the present work aims at providing an intercomparison between the EFFIS and MODIS burnt area operational products for the Greek fires that occurred from 2005 to 2007. A further objective is to explore for the same temporal interval the burnt area estimates from the two products relative to land use/cover and elevation. Our study makes available a rigorous and multi-faceted analysis of the burnt area spatial agreement between the two datasets compared. At the same time, it extends in both the temporal and spatial domains as well as in depth of analysis conducted in an analogous intercomparison study conducted earlier by Boschetti et al. (2008). Last but not least, it facilitates a complementary work to existing approaches concerning the evaluation of mapping the burnt areas at the national level, a topic of sustained interest even today (Kontoes et al., 2009; Veraverbeke et al., 2010; Sifakis et al., 2011; Petropoulos et al., 2012).

\section{Study area}

Our study area covers the country of Greece, both the mainland and island area $\left(39^{\circ} \mathrm{N}-19^{\circ} \mathrm{E} ; 36^{\circ} \mathrm{N}-28^{\circ} \mathrm{E}\right)$. Greece is a country representative of typical Mediterranean conditions in terms of landscape structure and land surface cover variation. The terrain structure of the country varies widely from sea level to approximately $3000 \mathrm{~m}$, having steep slopes especially in the northern and southern parts of the country. Vegetation in the country also varies due to the large altitude difference. At lower elevations are found mainly sclerophyllous vegetation, sparsely vegetated areas, agricultural and urban 
areas. At higher altitudes, areas are covered mainly by different forest types as well as transitional woodland/shrubland. The country is also characterised by a Mediterranean type of temperate climate, with cool, wet winters and hot, dry summers with a long dry period starting in April and lasting until September.

Fire activity in Greece generally starts in late spring (May) and ends in early autumn (September). The peak fire activity is observed during the months of July and August, which is the driest season with the highest average temperatures in Greece. This is because the prolonged arid and hot summer periods generally favour the ignition and rapid propagation of fires especially with strong winds, resulting in large burnt areas every year. A long-term analysis of wildland fires in Greece conducted recently by Boboulos and Purvis (2009) shows that for the period between 1955 and 1999 up to 11500 ha burnt out on average per year up to the year 1973 . Approximately a third of this area was forest, and the rest was partly shrubland and partly grass. Following 1974 , significant increase in the surface area burnt by fires has been observed, and this upward trend continues today with the worst year for wildland fires ever recorded in Greece in 2007 (Boboulos and Purvis, 2009).

\section{Datasets}

\subsection{MODIS burnt area product}

The MODIS burnt area product (MCD45A1) is one of the several MODIS suite land surface products (Justice et al., 2002). It is a monthly gridded product that provides burnt area estimates at a spatial resolution of $500 \mathrm{~m}$ derived by consideration of temporal changes in surface reflectance based on a method described by Roy et al. (2005). The burnt area extraction algorithm is implemented separately to geolocated pixels over a long time series of reflectance observations. In the algorithm, a bi-directional reflectance model is inverted against multi-temporal reflectance observations to supply predicted reflectance values and uncertainties for successive observations. In the next step, the change in reflectance from a previously observed state is quantified based on the computation of a statistical measure between the observed bi-directional surface reflectance (BRF) and the predicted BRF at the viewing and illuminating angles of the observation. If large discrepancies are observed, then those are attributed to change, and a temporal constraint is used to differentiate between temporary changes (e.g. shadows) spectrally similar to more-persistent changes induced by fire. The detection of the date of burning is constrained by the frequency and occurrence of missing observations, and to reflect this the algorithm is run to report the burn date with an 8-day precision. The MCD45A1 product is produced in the standard MODIS Land tile format and WGS84 datum. Each tile has fixed earth location, covering approximately
$1200 \times 1200 \mathrm{~km}$. The product is available in either geotiff or hdf format. Each product tile contains per pixel burning information on the approximate Julian day of burning, or a code indicating unburnt, or no burning detected but snow detected, or no burning detected but water detected, or insufficient number of MODIS observations to make a detection decision (usually due to clouds or missing data), and ancillary processing path and quality information. The product is freely distributed either via NASA's Warehouse Inventory Search Tool (WIST) or via an ftp server operated by the MODIS fire team (http://modis-fire.umd.edu/), starting from the year 1999. In our study the MOD45A1 geotiff image product for all months for the years 2005 to 2007 was acquired directly from the MODIS fire team ftp site.

\subsection{EFFIS burnt area product}

EFFIS with respect to burnt area mapping provides the rapid damage assessment (RDA) product. In this product, burnt area estimates are derived at $250 \mathrm{~m}$ spatial resolution from the daily processing of MODIS Terra and Aqua visible nearinfrared (VNIR) and shortwave (SWIR) data. Burnt area detection is assisted by the MODIS $1 \mathrm{~km}$ active fire product (Giglio et al., 2003). Burnt areas occurring in agricultural land as defined by the CORINE 2000 land cover map (JRCEEA, 2005) are masked out during the algorithm implementation (Boschetti et al., 2008). The whole process is also assisted by visual image interpretation and by the systematic collection of fire news from various European media sources (Barbosa et al., 2006). The EFFIS RDA has been implemented since 2003 and provides the daily update of the perimeters of burnt areas in Europe for fires of about 40 ha or larger, although the product may also include the perimeters of burnt areas of smaller dimension. The product is provided by EFFIS via a web interface (http://effis-viewer.jrc. ec.europa.eu/wmi/viewer.html), but potential users can also request those products directly from EFFIS. In our study, the annual burnt area estimates from the EFFIS RDA product for the years 2005 to 2007 was acquired directly from the EFFIS team. In total, three files were provided, each corresponding to the yearly burnt area map included in our analysis. Each file was delivered in vector format (shapefile) and at LAEAETRS89 projection.

\subsection{CORINE 2000}

CORINE (JRC-EEA, 2005) is a project that was created in 1985 by the European Union with the aim to create a European land cover/land use (LCLU) map, derived primarily from the interpretation of satellite images and ancillary data. CORINE 2000 consists of an updated version of the initial CORINE product providing land use/cover maps of 29 European countries derived from the processing of orthorectified LANDSAT images. This CORINE version is at present updated to the CORINE 2006 land cover map. However, this 


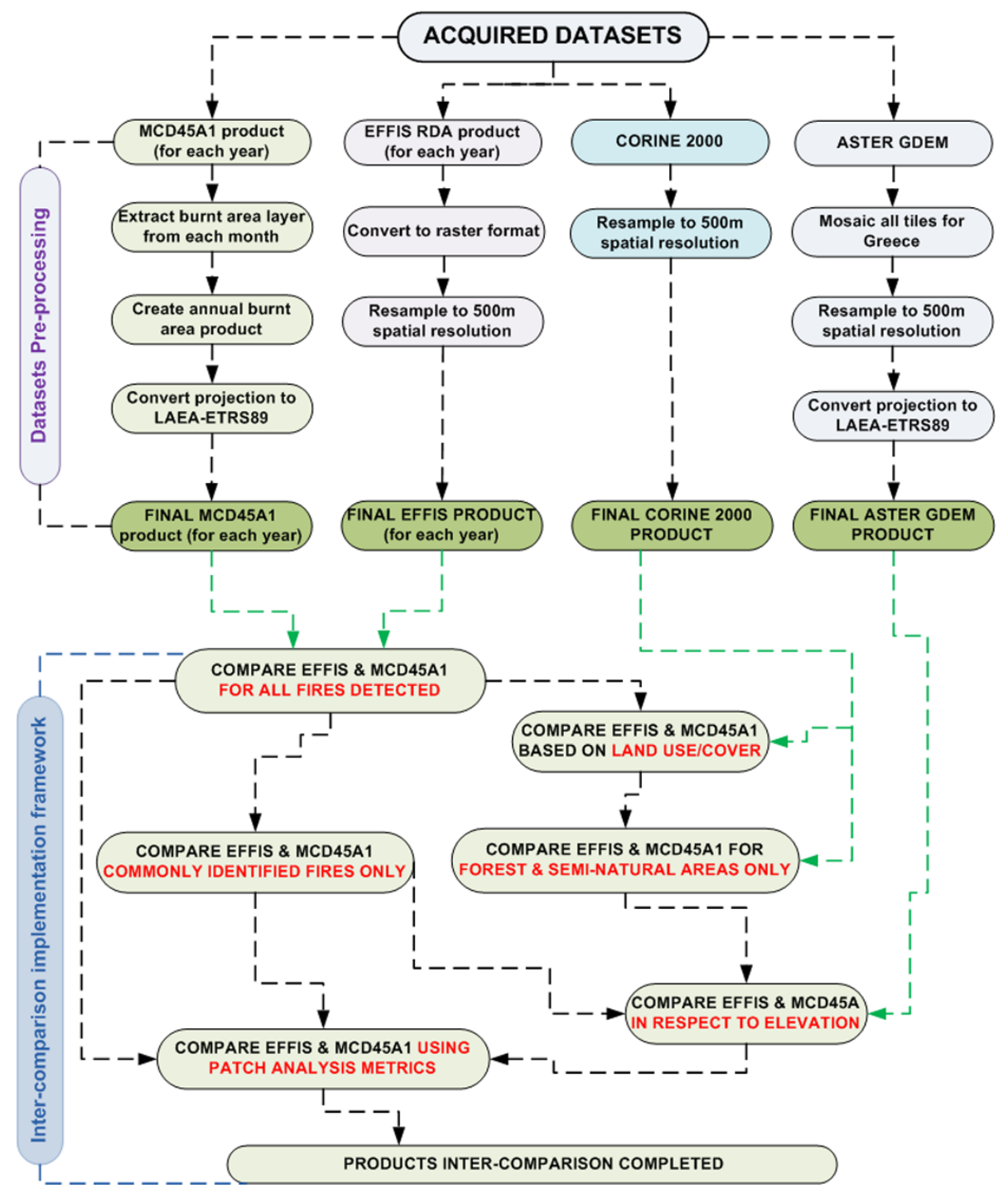

Fig. 1. Overview of the methodology implemented in the present study, in terms of both data pre-processing and their intercomparison.

version is still in preparatory phase in some countries including Greece. As a result, land use/cover information from CORINE 2000 was utilised in the present study. This was also the same LULC base map used by EFFIS to mask out the fires that occurred in agricultural areas, as described previously (Sect. 3.2). We used specifically the $250 \mathrm{~m}$ spatial resolution raster dataset provided at no cost from the European Environmental Agency website (http://www.eea.europa.eu/ data-and-maps/data/corine-land-cover-2000-raster-1) as a georeferenced dataset at ETRS1989 datum and projection.

\subsection{ASTER Digital Elevation Model}

Information on elevation was obtained from the global digital elevation model (GDEM) of the Advanced Spaceborne Thermal Emission and Reflection Radiometer (ASTER) sensor. The ASTER GDEM product was released in 2009 and was updated (Version 2) at the end of 2011. It provides information on elevation between $83^{\circ} \mathrm{N}$ and $83^{\circ} \mathrm{S}$ with geographic latitude-longitude coordinates at 1 arc sec $(30 \mathrm{~m})$ grid. Estimated accuracies of the product are for $20 \mathrm{~m}$ at $95 \%$ confidence for vertical data and $30 \mathrm{~m}$ at $95 \%$ confidence for horizontal data (ASTER GDEM, 2009). The dataset is provided in geotiff format, in geographic lat/lon projection and WGS84/EGM96 datum. It is available at no cost to users via electronic download from the Earth Remote Sensing Data Analysis Center (ERSDAC) of Japan and from NASA's Land Warehouse Inventory Search Tool (now replaced by REVERB, http://reverb.echo.nasa.gov/reverb). The ASTER GDEM is distributed as separate tiles of elevation covering Earth. In our study, the tiles covering Greece were acquired from WIST. 


\section{Methods}

\subsection{Pre-processing}

Given the differences between the collected data in terms of their format as well as their projections, some pre-processing was necessary to standardise those before intercomparisons were performed. Most of the acquired datasets were in vector format and had been provided at LAEA-ETRS89 projection, which is also commonly used for European product distribution according to the INSPIRE Directive. On this basis, a decision was made to adopt the same specifications in terms of data format and projection for all our collected datasets. All pre-processing and geospatial analysis of the spatial datasets was carried out in ENVI (v. 4.7, ITT Visual Solutions) and ArcMap (v. 10.1, ESRI) software platforms. The main steps involved in the acquired datasets' pre-processing are illustrated in Fig. 1.

In the monthly MCD45A1 product, first the layer corresponding to the burnt area estimate was extracted from the different layers of information embedded in the datasets. The 12 image layers, each corresponding to a month of each year, included in our analysis were then merged, forming three single files, each corresponding to the burnt area map for each year. Next, each of the three raster image files was re-projected to the LAEA-ETRS89 projection. On the other hand, the EFFIS burnt area vector file from each year of analysis was converted to raster with a cell resolution of $500 \mathrm{~m}$ since most of the data was collected in this format and resolution, retaining the original projection. The final MCD45A1 and EFFIS burnt area maps for the year 2007 are shown in Fig. 2 as an example.

CORINE 2000 land use/cover map was re-sampled to a spatial resolution of $500 \mathrm{~m}$. The ASTER GDEM product tiles of Greece using image mosaic were merged into a single file. This latter dataset was subsequently re-projected to LAEAETRS89 projection and was re-sampled by the nearest neighbour to a spatial resolution of $500 \mathrm{~m}$ to match the MCD45A1 spatial resolution. Figure 3 illustrates the CORINE 2000 and final ASTER GDEM maps used in our study after the end of data pre-processing.

\subsection{Intercomparison approach}

The conceptual framework of the main analysis steps followed in performing the intercomparison between the EFFIS and MCD45A1 products is also depicted in Fig. 1. All the pre-processed layers were used in performing the intercomparison of the burnt area estimates for the time interval of the years 2005-2007. First comparisons were conducted between the burnt area products for the whole extent of Greece for each year of analysis, examining also the differences in the burnt area estimates relative to land cover. Subsequently, comparisons between the two operational products were focused only in forested and semi-natural areas, as
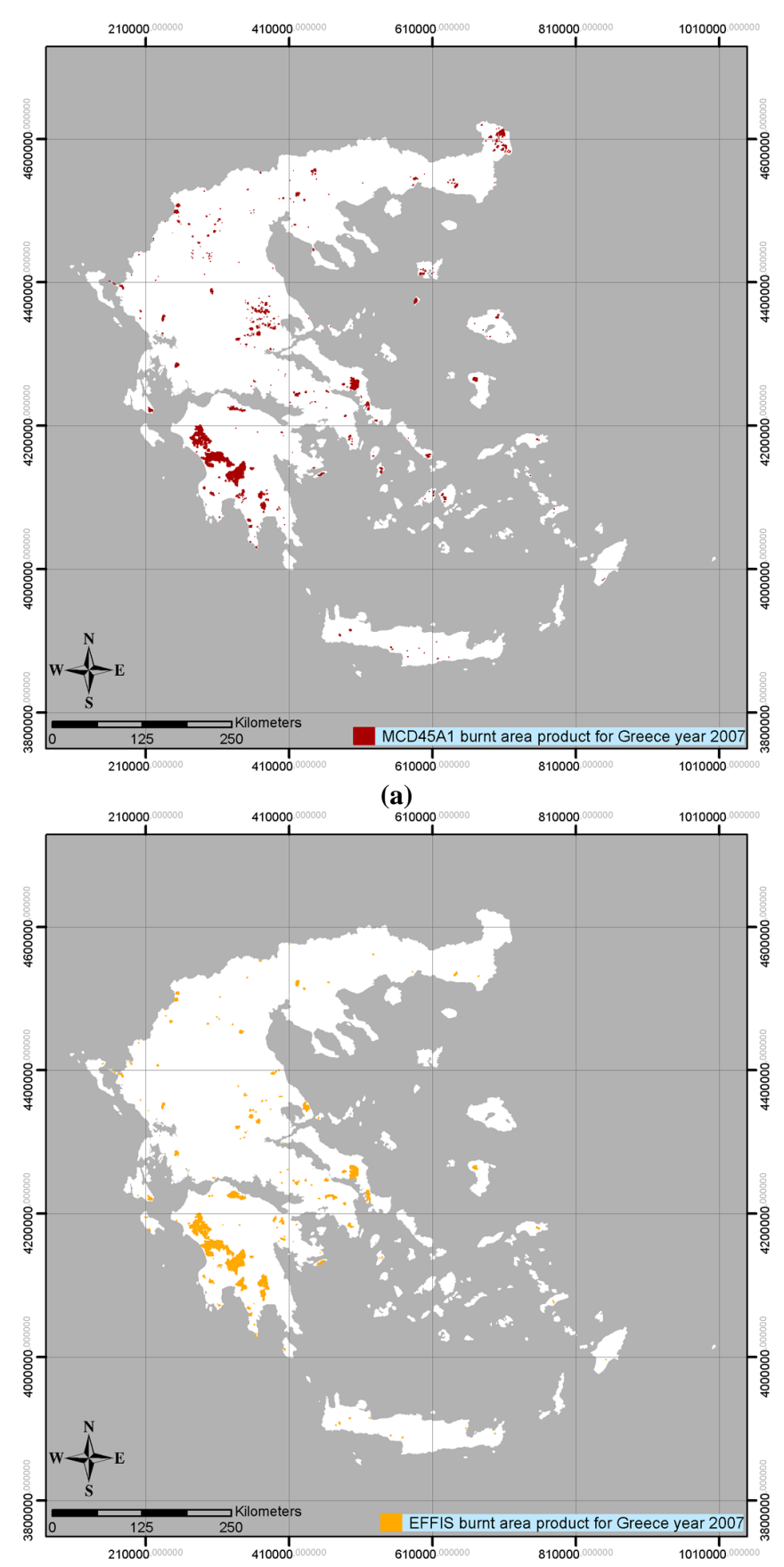

(b)

Fig. 2. Examples of final burnt area products derived derived from the (a) MCD45A1 and (b) EFFIS for the year 2007 after the preprocessing completion.

defined according to CORINE 2000 Level 1 nomenclature (JRC-EEA, 2005). This was deemed necessary, given that EFFIS is meant to map fires occurring in those land cover types (Sect. 3.2). For this data subset, further comparisons were performed to evaluate burnt area agreement between the two datasets relative to elevation. Then, another aspect of 


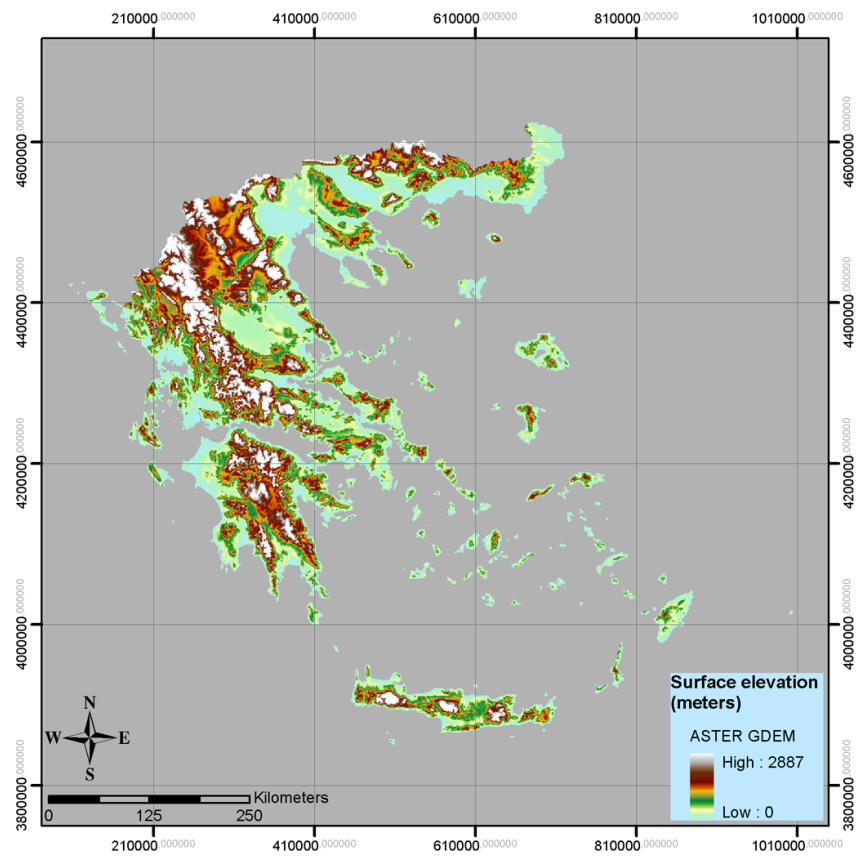

(a)

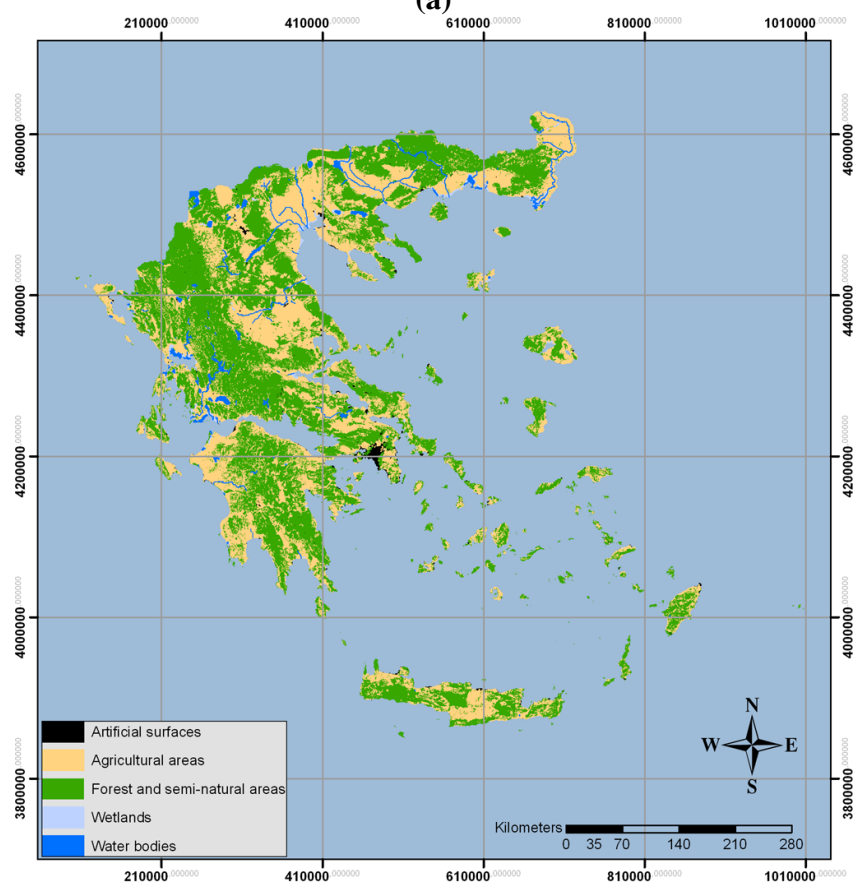

(b)

Fig. 3. The digital elevation model of Greece derived from the ASTER GDEM (a, above) as well as the CORINE 2000 (b, below) used in our analysis after the pre-processing completion.

analysis was to focus on comparisons of the commonly identified fires between the two datasets: the fires that included essentially all occasions in which at least one common part of the fire was detected by both products. This complementary analysis aimed at further interpreting the differences between the two products in relation to fires' spatial configuration (i.e. fragmentation). Thus, for this subset of data, fires were analysed by using patch metrics (McGarigal and Marks, 1995), namely number of patches, mean patch size and perimeter as well as elevation.

All analysis was conducted in ArcMap (v. 10.1, ESRI), a geographical information system (GIS) environment with raster and/or vector analysis capabilities. Comparisons of burnt area estimates with respect to parameters such as land use/cover or elevation were conducted by simply intersecting for each year of analysis the burnt area map from each operational product with the parameter of interest. The remainder of the paper is focused in presenting and discussing the results obtained from the intercomparison conducted between the two products.

\section{Results}

The agreement in the burnt area estimates between the two operational datasets for all years of analysis was examined by computing a series of statistical metrics, following an approach similar to Boschetti et al. (2008). Generally, the two products differed noticeably in their burnt area estimates, especially in the years 2005 and 2006 (Table 1a). In 2005 and 2006, the MCD45A1 product provided a higher "total burnt area" estimate in comparison to EFFIS, whereas the opposite was the case for 2007. In addition, "total common burnt area" between the MCD45A1 and EFFIS was in all years of our analysis lower than the "total not commonly detected burnt area". The "commonly detected burnt area" between the two datasets was much higher for the years 2006 and 2007 in comparison to 2005. Similar trends in the comparisons were observed as well for the "total not common burnt area". It is worthwhile to mention that for 2005 and 2006 the total not common burnt area was approximately 28 and seven times higher, respectively, than the total common burnt area, but for the year 2007 no significant differences were found. These differences between the two burnt area products found were also seen in their spatial comparisons as well, illustrated in Fig. 4. In this figure, the commonly identified burnt area between the two datasets is depicted in blue, the burnt area identified only by MCD45A 1 in red and that only by EFFIS and not by MCD45A1 in orange. Evidently, noticeable differences were also found between the two datasets for all years in terms of both fire detection and burnt area estimates except for 2007, when a closer agreement was identified. Interestingly, as can also be observed (Fig. 4), a generally close agreement spatially between the two datasets was observed in some geographical regions, especially for the year 2007.

Subsequently, differences in the burnt area estimates between the two products were examined with respect to land use/cover (Table 2), adopting the land use/cover classes categorisation corresponding to the CORINE Land Cover 2000 Level 1 land nomenclature (JRC-EEA, 2005). Clearly, the two operational products closely agreed as regards the main 
Table 1. Summarised statistics of the burnt area estimates between the two products for the years 2005-2007. Burnt area is expressed in ha.

\begin{tabular}{|c|c|c|c|c|c|c|}
\hline Year & $\begin{array}{r}\text { Total burnt } \\
\text { area as mapped } \\
\text { by MCD45A1 }\end{array}$ & $\begin{array}{r}\text { Total burnt } \\
\text { area as mapped } \\
\text { by EFFIS }\end{array}$ & $\begin{array}{r}\text { Total burnt area as } \\
\text { mapped by MCD45A1 } \\
\text { and not by EFFIS }\end{array}$ & $\begin{array}{r}\text { Total burnt area } \\
\text { as mapped by EFFIS } \\
\text { and not by MCD45A1 }\end{array}$ & $\begin{array}{r}\text { Total common burnt } \\
\text { area as mapped by } \\
\text { both MCD45A1 \& EFFIS }\end{array}$ & $\begin{array}{r}\text { Total burnt area } \\
\text { not common between } \\
\text { MCD45A1 \& EFFIS }\end{array}$ \\
\hline \multicolumn{7}{|c|}{ (A) Burnt area comparisons for all fires included in each dataset } \\
\hline 2005 & 26268 & 4517 & 25224 & 3473 & 1044 & 28697 \\
\hline 2006 & 22648 & 16355 & 17928 & 11634 & 4721 & 29562 \\
\hline 2007 & 228114 & 271540 & 68684 & 111109 & 160431 & 178793 \\
\hline \multicolumn{7}{|c|}{ (B) Burnt area comparisons for only the "forest and semi-natural" areas } \\
\hline 2005 & 3982 & 2506 & 3322 & 1846 & 660 & 5168 \\
\hline 2006 & 5435 & 10565 & 2293 & 7423 & 3142 & 9716 \\
\hline 2007 & 103252 & 158609 & 21618 & 76975 & 81634 & 98592 \\
\hline \multicolumn{7}{|c|}{ (C) Burnt area comparisons for "commonly detected fires" only } \\
\hline 2005 & 3048 & 2389 & 2004 & 1345 & 1044 & 3349 \\
\hline 2006 & 5825 & 14703 & 1104 & 9983 & 4721 & 11087 \\
\hline 2007 & 185861 & 258257 & 25430 & 97827 & 160431 & 123257 \\
\hline
\end{tabular}

land use/cover types identified as burnt areas. Indeed, for both products, of the five land cover classes, fires had mainly occurred in "agricultural" and "forest and semi-natural" areas. However, in absolute terms, MCD45A1 detected most fires in agricultural areas, followed by forest and semi-natural areas, while the reverse was observed in the EFFIS estimates. For 2005, according to MCD45A1, fires in agricultural areas were about six times more prevalent than fires in forest and semi-natural areas; for 2006 they were approximately three times more prevalent, but for 2007 were much more similar. On the other hand, EFFIS burnt areas between agricultural and forest and semi-natural areas were generally more similar, apart from the 2006 fires in which forest and semi-natural areas were nearly two times as prevalent as the fires in agricultural areas.

Further analysis was conducted examining the burnt area estimates from the two products but only for forests and semi-natural areas (Table 1b), since EFFIS is meant to detect primarily fires occurring in those specific land cover types (Sect. 3.2). The general trends in the agreements between the different years were also similar to those observed when the burnt areas from all fires had been compared (shown in Table 1a). The differences between the two products were still evident, but noticeably smaller compared to when all land use/cover types had been considered (Table 1a). This is indicated for example from the dramatic decrease of the differences in the total common and not common burnt area estimates between the two products for the years 2005 and 2006.

For this specific data subset, additional comparisons performed aimed at exploring how burnt area detected from each dataset was distributed across different elevation ranges (Table 3a). Generally, for each year, both products showed similar trends in terms of the total burnt area detected at the different elevation ranges. For both datasets in the years 2005 and 2006 most of the fires occurred in the elevation range
0-250 $\mathrm{m}$, followed by the $251-500 \mathrm{~m}$ elevation range, with very few fires occurring at higher altitudes. However, interestingly fires were equally distributed between the different elevation classes in the year 2007. In addition, for the years 2005 and 2007, the MCD45A1 product provides higher burnt area estimates in comparison to EFFIS in the low-elevation range, whereas the opposite was the case for 2006. In higheraltitude ranges no clear trend is observed.

To further evaluate the agreement between the two burnt area products, we also conducted analysis of their estimates with respect to the "commonly detected fires" only (Table 1c). In terms of the total burnt area comparisons, similar results to those found previously for the case of the forest and semi-natural area comparisons only were obtained. In terms of the fires distribution with respect to elevation (Table $3 \mathrm{~b}$ ), results were again largely similar to those obtained in the forest and semi-natural area comparisons analysed previously (Table 3a). Indeed, most of the fires for both products appeared to also occur most commonly at lower elevations (i.e. 0-250 $\mathrm{m}$ and $250-500 \mathrm{~m}$ ). Yet, it should be pointed out that especially for 2007 the fires mapped from both products were equally distributed along the different elevation ranges.

Burnt area agreement between the two datasets was further evaluated based on patch analysis. Various patch analysis metrics (McGarigal and Marks, 1995) were computed for all possible analysis scenarios previously examined (i.e. the total burnt area estimated from each product, the subset of the forest and semi-natural areas only and the commonly identified fires only). The results from this analysis for all years of comparison are made available in Table 4. Interestingly, our results generally showed a generally much lower number of patches detected by EFFIS in comparison to MCD45A1, whereas the reverse was the case for the mean patch size and the mean patch perimeters. This appeared to be the case in all the different subsets of datasets examined except when comparing burnt areas in commonly detected fires for the year 

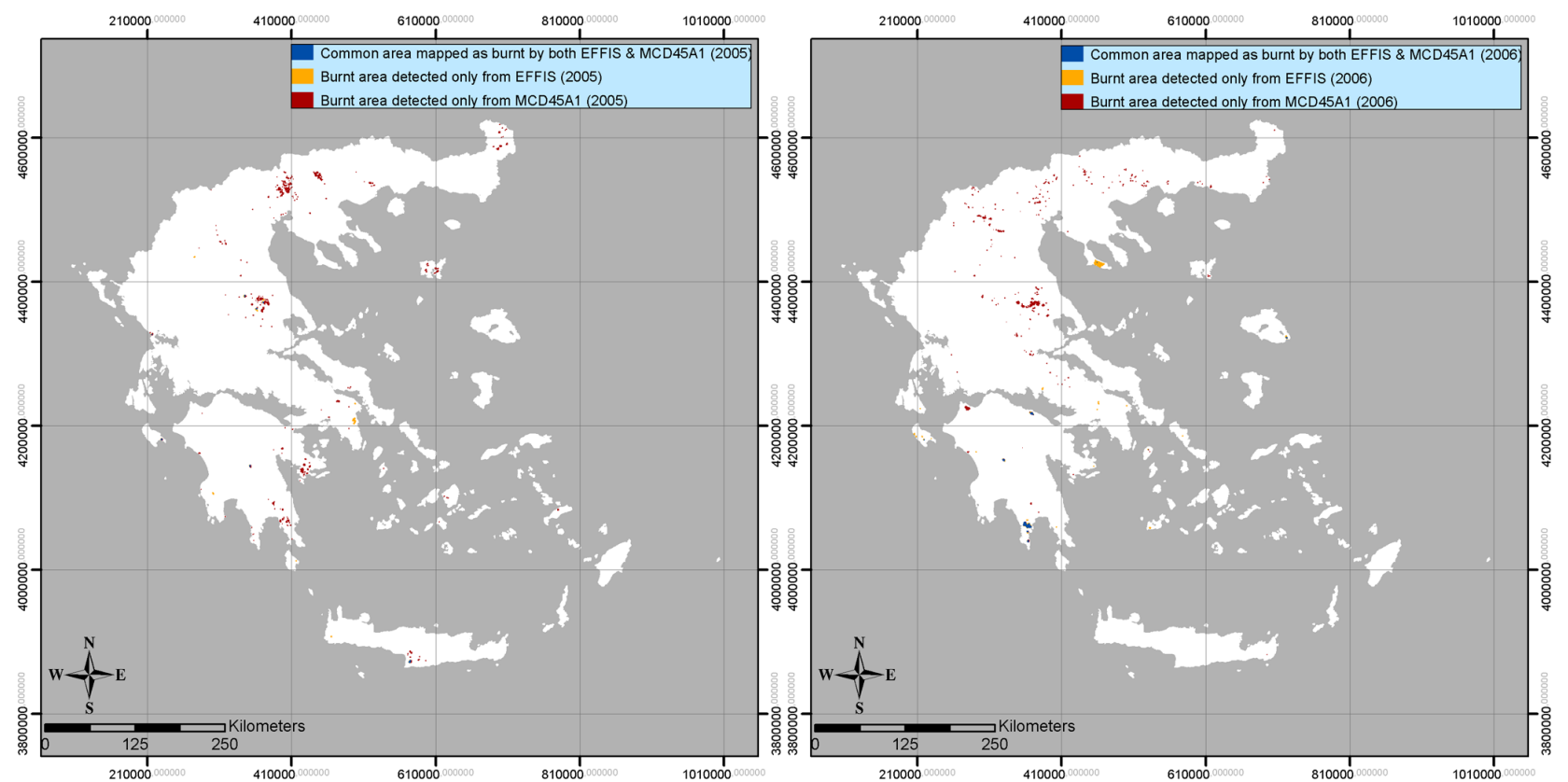

(a)

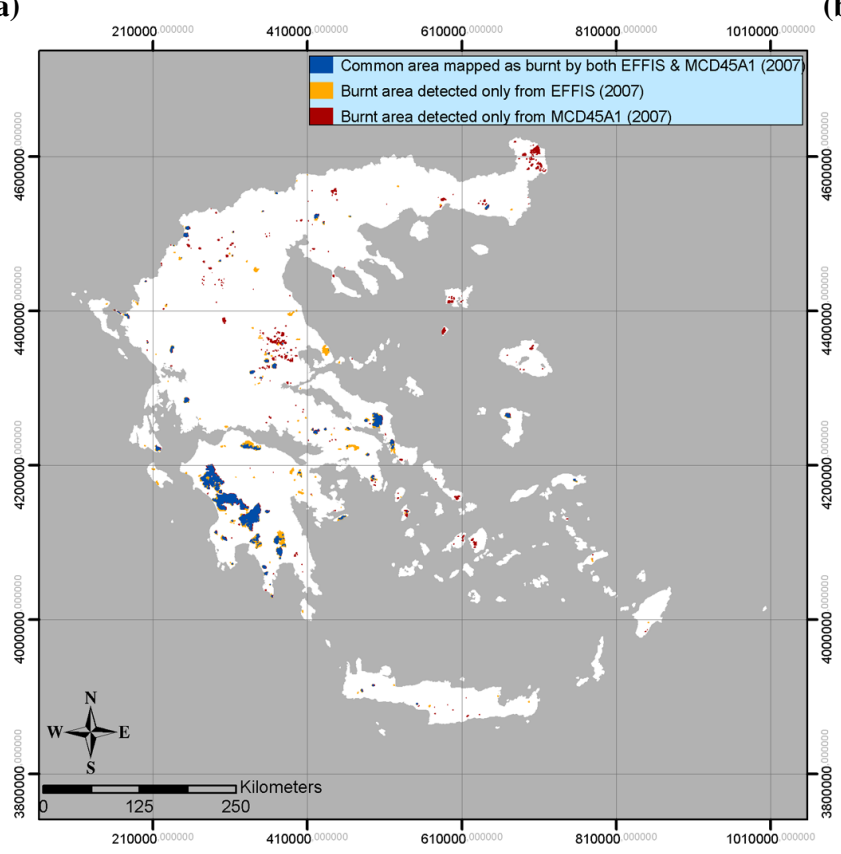

(c)

Fig. 4. Comparisons of the burnt area estimates for Greece between MCD45A1and EFFIS operational products for (a) 2005, (b) 2006 and (c) 2007 .

2005. The number of patches was found to be dramatically different between the two products when the comparisons were conducted for all fires mapped by each product without previous filtering, and also for the dataset subset comprising the forest and semi-natural areas only. For the dataset subset of commonly detected fires, the number of patches between the two products was significantly different only for the year 2007.

\section{Discussion}

The availability of burnt area operational products from both the MCD45A1 and EFFIS datasets for the region of Greece for the same temporal interval of the years 2005-2007 enabled us to rigorously evaluate their agreement. In general, total burnt area estimates between the two products were noticeably different not only in absolute values of burnt areas 
Table 2. Burnt area distribution (expressed as \%) from both MCD45A1 \& EFFIS operational products for the years 2005-2007 based on the CORINE 2000 land use/cover map.

\begin{tabular}{|c|c|c|c|c|c|c|}
\hline \multicolumn{7}{|c|}{ Total burnt area detected (\%) by each product for the different land use/cover types } \\
\hline Land use/cover & MCD45A1 (2005) & EFFIS (2005) & MCD45A1 (2006) & EFFIS (2006) & MCD45A1 (2007) & EFFIS (2007) \\
\hline Artificial surfaces & 1.7 & 4.7 & 1.0 & 0.2 & 1.2 & 1.1 \\
\hline Agricultural areas & 84.8 & 44.5 & 76.0 & 35.4 & 54.7 & 41.6 \\
\hline Forest and semi-natural areas & 13.2 & 50.8 & 22.7 & 64.4 & 43.5 & 57.1 \\
\hline Wetlands & 0.0 & 0.0 & 0.1 & 0.0 & 0.2 & 0.1 \\
\hline Water bodies & 0.3 & 0.0 & 0.2 & 0.0 & 0.4 & 0.1 \\
\hline Total & 100.0 & 100.0 & 100.0 & 100.0 & 100.0 & 100.0 \\
\hline
\end{tabular}

Table 3. Burnt area mapped by MCD45A1 \& EFFIS operational products for the years 2007, 2006 and 2005 for the different elevation ranges derived from the ASTER GDEM operational product.

\begin{tabular}{|c|c|c|c|c|c|c|}
\hline \multirow{3}{*}{ Elevation classes (m) } & \multicolumn{6}{|c|}{$\begin{array}{l}\text { (A) Comparisons with respect to elevation for the subset of } \\
\text { "forest and semi-natural" areas only }\end{array}$} \\
\hline & MCD45A1 (2005) & EFFIS (2005) & MCD45A1 (2006) & EFFIS (2006) & MCD45A1 (2007) & EFFIS (2007) \\
\hline & \multicolumn{6}{|c|}{$\%$} \\
\hline $0-250$ & 59.9 & 48.9 & 42.9 & 61.3 & 23.6 & 19.4 \\
\hline $251-500$ & 26.3 & 27.7 & 32.1 & 29.3 & 28.3 & 30.1 \\
\hline $501-750$ & 1.6 & 10.9 & 11.9 & 7.1 & 26.1 & 24.4 \\
\hline $751-2250$ & 12.2 & 12.5 & 13.2 & 2.3 & 22.1 & 26.1 \\
\hline Total & 100.0 & 100.0 & 100.0 & 100.0 & 100.0 & 100.0 \\
\hline
\end{tabular}

(B) Comparisons with respect to elevation for the subset of "commonly detected fires" only

\begin{tabular}{|c|c|c|c|c|c|c|}
\hline \multirow{2}{*}{ Elevation classes (m) } & MCD45A1 (2005) & EFFIS (2005) & MCD45A1 (2006) & EFFIS (2006) & MCD45A1 (2007) & EFFIS (2007) \\
\hline & \multicolumn{6}{|c|}{$\%$} \\
\hline $0-250$ & 52.3 & 48.0 & 51.6 & 69.9 & 33.5 & 32.4 \\
\hline $251-500$ & 30.5 & 41.7 & 34.7 & 23.0 & 31.9 & 31.4 \\
\hline $501-750$ & 1.8 & 4.1 & 8.3 & 5.4 & 21.6 & 20.2 \\
\hline $751-2250$ & 15.4 & 6.2 & 5.4 & 1.8 & 13.0 & 16.0 \\
\hline Total & 100.0 & 100.0 & 100.0 & 100.0 & 100.0 & 100.0 \\
\hline
\end{tabular}

detected but also spatially. This was the case for all years in which comparisons were included in our analysis.

The differences between the products can be related to the specifications of the two products. The MCD45A1 burnt area detection algorithm used cannot distinguish between the wildland fires and agricultural practices. On the other hand, EFFIS was designed to map burnt area occurring primarily in forested and semi-natural areas. Burning crop residue is historically a widespread practice throughout many areas of the world, including Mediterranean regions, used for small-grain production such as rice, grass and wheat (Kamm and Montgomery, 1990; Eagle et al., 2000; Darby and Yeoman, 1994; Prasad et al., 1999). In Greece, fire is an agricultural practice commonly adopted by farmers, for example to clear up and pesticide their fields before planting a new crop. Indeed, as was revealed in our analysis, differences in the total burnt area were noticeably decreased when comparisons between the two products were conducted for the subset of data covering only the forest and semi-natural areas. This perhaps also partially explains the obvious differences in the burnt area estimates for the years 2005 and 2006 in comparison to 2007 since that year the catastrophic fires occurred mostly in forest and semi-natural rather than agricultural areas. However, since differences in the burnt area estimates persisted even after comparisons had been focused only on the forest and semi-natural areas subset of data, the differences in the two products' burnt area estimates should be attributed to other factors as well.

Another possible reason explaining their differences can be related to the spatial, spectral and temporal properties of the fires in relation to the spatial and spectral configuration of the MODIS sensor which is used to detect the burnt 
Table 4. Patch metrics analysis conducted for different dataset subset scenarios comparing the burnt area estimates from the MCD45A1 \& EFFIS operational products for the years 2005-2007.

\begin{tabular}{|c|c|c|c|c|c|c|}
\hline & \multicolumn{2}{|c|}{2005} & \multicolumn{2}{|c|}{2006} & \multicolumn{2}{|c|}{2007} \\
\hline & MCD45A1 & EFFIS & MCD45A1 & EFFIS & MCD45A1 & EFFIS \\
\hline & \multicolumn{6}{|c|}{ (A) Burnt area comparisons for all fires included in each dataset } \\
\hline Number of patches & 238 & 15 & 233 & 25 & 391 & 142 \\
\hline Patch total perimeter $(\mathrm{km})$ & 1081.2 & 116.8 & 861.9 & 210.4 & 3679.8 & 2365.6 \\
\hline Mean patch area (ha) & 110.4 & 301.1 & 97.2 & 654.2 & 583.4 & 1912.3 \\
\hline \multirow[t]{2}{*}{ Patch mean perimeter $(\mathrm{km})$} & 4.54 & 7.78 & 3.69 & 8.41 & 9.41 & 16.65 \\
\hline & \multicolumn{6}{|c|}{ (B) Comparisons for the "forest and semi-natural" areas only } \\
\hline Number of patches & 129 & 25 & 133 & 90 & 999 & 1.032 \\
\hline Patch total perimeter $(\mathrm{km})$ & 336.5 & 126.9 & 428.5 & 567.3 & 6023.0 & 8079.4 \\
\hline Mean patch area (ha) & 30.9 & 100.2 & 40.9 & 117.4 & 103.4 & 153.7 \\
\hline \multirow{2}{*}{ Patch mean perimeter $(\mathrm{km})$} & 2.6 & 5.07 & 3.22 & 6.3 & 6.02 & 7.82 \\
\hline & \multicolumn{6}{|c|}{ (C) Burnt area comparisons for the "commonly detected fires" only } \\
\hline Number of patches & 7 & 7 & 11 & 9 & 118 & 70 \\
\hline Patch total perimeter $(\mathrm{km})$ & 84.5 & 59.6 & 114.0 & 147.9 & 2269.1 & 1963.2 \\
\hline Mean patch area (ha) & 435.4 & 341.3 & 529.5 & 1633.7 & 1575.0 & 3689.3 \\
\hline Patch mean perimeter $(\mathrm{km})$ & 12.06 & 8.51 & 10.36 & 16.43 & 19.22 & 28.04 \\
\hline
\end{tabular}

area in both products (Eva and Lambin, 2000; Boschetti et al., 2004). In Greece in particular, vegetation is highly fragmented and non-homogenous. Such land surface characteristics have generally an important impact on the accuracy of burnt area maps, especially those produced from coarseresolution remote sensing data such as in our case MODIS (Giglio et al., 2003; Roy et al., 2005). This is because burnt areas are not so easily detectable from the surrounding environment, particularly at low spatial resolution (such as that of MODIS). This has generally shown to lead to an underestimation of the burnt area in coarser-resolution data (Silva et al., 2005). With respect to that, it is underlined that our patch analysis suggested a high difference in the degree of fire fragmentation between the two products, and this was the case for all scenarios of data comparison. Indeed, MCD45A1 always detected a significantly higher number of patches with a smaller mean area and perimeter in comparison to EFFIS, suggesting that it was able to detect much smaller fires. Yet, this does not necessary imply that EFFIS is not able to detect small fires in comparison to MCD45A1, since specifications between the two products delivered differ.

With respect to this, the differences in the spatial resolution in which the two products are originally distributed should be taken into account from different perspectives when attempting to explain the differences in their estimates. The different spatial resolution between the products compared should be included among the factors affecting the results in the direct intercomparison of the burnt area operational products. In addition, EFFIS includes a generalisation error on the fire vector map since it is a digitisation product.
As a result of this, non-burnt areas inside the burnt scar can be potentially marked as burnt on EFFIS. With respect to this, it should be mentioned that our patch analysis also showed that EFFIS was able to produce a much smaller number of patches but with a higher mean patch area and perimeter in comparison to the MCD45A1 product. Yet, the potential influence of format conversion to generalisation error must be properly investigated in evaluating the contribution of the generalisation error in the EFFIS dataset With respect to the MCD45A1 estimates.

Specifically for cases of years with low fire activity, such as those of 2005 and 2006 in Greece, some of the burnt area discrepancies between the two datasets might be explained by the fact that the extent of burnt areas in some cases can be very limited (and thus difficult to detect), resulting in higher relative influence of residual noise from the surrounding environment (Boschetti et al., 2004; Trigg and Roy, 2007). This can potentially result in a higher generalisation error occurring in the cases of smaller fires in particular. It is noted that our results showed a comparatively close agreement in the burnt areas detected between the two products for the year 2007, a year of very high fire activity, in comparison to 2005 and 2005 .

Our results agree as well with other analogous intercomparison experimental studies of burnt area operational products. For example, Boschetti et al. (2004) in an intercomparison study for the same time period between the GBA 2000 and GlobScar burnt area products and of the World Fire Atlas fire product, all derived from low-resolution remote sensing data, reported a large disagreement in terms of their areal 
estimates. Authors attributed the differences they observed to the low spatial resolution of the remote sensing data (i.e. $1 \mathrm{~km}$ ) that allowed only large fires to be detected, but also to the different number of available overpasses and the different algorithms employed. Boschetti et al. (2008) conducted an intercomparison between the MCD45A1 and EFFIS burnt area products for the summer of 2007 only for the region of Peloponnese in Greece. Authors reported the total burnt area from EFFIS to be somehow lower in comparison to that reported by MCD45A1 for the same time and spatial domain. Noticeably, the total area mapped as burnt by MCD45A1 only and not by EFFIS was herein reported to be approximately $40 \%$ larger in comparison to that mapped as burnt only by EFFIS and not by the MCD45A1 product, suggesting that perhaps MCD45A1 also detects fires occurring from man-made practices. In their study, Boschetti et al. (2008) noted that most of the differences occurred along the borders of EFFIS-mapped polygons, as well as in agricultural regions which were not considered by EFFIS, and in cases of small burnt areas mapped by EFFIS but not by MCD45A1.

\section{Conclusions}

In this paper a rigorous and systematic intercomparison of the MCD45A1 and EFFIS burnt area operational products provided by the USA's NASA and the Joint Research Centre of the European Commission, respectively, was undertaken. A further objective was to evaluate the agreement in the two products' estimates as a function of land use/cover type and topography parameters. As a case study, the Greek wildland fires of 2005 to 2007 were used.

Noticable differences in the burnt area estimates between the two datasets were found herein, both spatially and in absolute accuracies for all the years included in our analysis. Comparisons did not show any clearly conclusive patterns in terms of burnt area estimates, making it unworkable to derive definite conclusions as regards the overestimation or underestimation of one product over the other in mapping burnt areas. Relationships between the burnt area estimates and land use/cover as well as elevation showed as well generally different, but largely explainable, differences between the two products. Possible interpretations of the differences in the burnt area estimates between the examined datasets were also discussed. Some of those included the differences in their mapping methodologies (e.g. land cover types in which burnt areas are mapped, minimum mapping unit) combined with the distinct fires characteristics in Greece (e.g. widely used component in farming practices in the country, highly dynamic vegetation landscapes fragmentation).

Our findings generally also agree as well to other studies performing analogous comparisons of the same or similar operational products. Our work, however, is the first of its kind that provides such comprehensive and rigorous intercomparison between operational products currently available, particularly in a Mediterranean setting. Yet, it should be underlined that the lack of precise agreement in the burnt area estimates between the two datasets found here does not necessarily mean that one or the other is inaccurate. It rather points to the need for their calibration using high-resolution data, something that has also been underlined previously by other investigators (e.g. Boschetti et al., 2004). All in all, our study builds upon a series of analogous validation exercises carried out using burnt area products distributed by different agencies/services. At the same time, it supports focusing efforts globally towards the development of standardised validation methodologies required for validating regional fire analysis operational products available at present or planned to be distributed from future-generation satellites.

Acknowledgements. We would like to thank all the providers of the EFFIS and MODIS burnt area products as well as of CORINE 2000 and the ASTER GDEM for making their products available for free publicly. EFFIS data were provided by the European Forest Fire Information System (EFFIS; http://effis.jrc.ec.europa.eu) of the European Commission's Joint Research Centre. G. P. Petropoulos thanks INFOCOSMOS E.E. (http://www.infocosmos.eu/rsgis/index.html) for support provided during the period of this work preparation. We would also like to acknowledge the reviewers for their constructive feedback that improved the originally submitted manuscript.

Edited by: A. Lanorte

Reviewed by: two anonymous referees

\section{References}

ASTER GDEM: ASTER GDEM Version, 1. Readme File available at: http://www.gdem.aster.ersdac.or.jp (last access: 24 July 2011), 2009.

Barbosa, P., Kusera, J., Strobl, P., Vogt, P., Camia, A., and SanMiguel-Ayanz, J.: European Forest Fire information System (EFFIS) - rapid damage assessment: appraisal of burnt area maps in southern Europe using MODIS data (2003 to 2005), Forest Ecol. Manage., 232, Supp. 1, pS218, 2006.

Boboulos, M. and Purvis, M. R. I.: Wind and slope effects on ROS during the fire propagation in East-Mediterranean pine forest litter, Fire Safety J., 44, 764-769, 2009.

Boschetti, L., Eva, H. D., Brivio, P. A., and Gregoire, J. M.: Lessons to be learned from the comparison of three satellite-derived biomass burning products, Geophys. Res. Lett., 31, L21501, doi:10.1029/2004GL021229, 2004.

Boschetti, L., Roy, D., Barbosa, P., Boca, R., and Justice, C.: A MODIS assessment of the summer 2007 extent burned in Greece, Int. J. Remote Sens., 29, 2433-2436, 2008.

Castillejo-González, L., López-Granados, F., García-Ferrer, A., Peña-Barragán, J. M., Jurado-Expósito, M., Sánchez de la Orden, M., and González-Audicana, M.: Object- and pixel-based analysis for mapping crops and their agro-environmental associated measures using QuickBird imagery, Comput. Electron. Agr., 68, 207-215, 2009. 
Cuomo, V., Lasaponara, R., and Tramutoli, V.: Evaluation of a new satellite-based method for forest fire detection, Int. J. Remote Sens., 22, 1799-1826, 2001.

Darby, R. J. and Yeoman, D. P.: Effects of methods of cereal straw disposal, seedbed preparation and sowing method on the establishment, yield and oil content of winter oilseed rape (Brassica napus), J. Agric. Sci., 122, 393-404, 1994.

Di Pasquale, G., Di Martino, P., and Mazzoleni, S.: Forest history in the Mediterranean region, in: Recent dynamics of Mediterranean vegetation and landscape, edited by: Mazzoleni, S., Di Pasquale, G., Mulligan, M., Di Martino, P., and Rego, F., New York: Wiley \& Sons, 13-20, 2004.

Eagle, A. J., Bird, J. A., Horwath, W. R., Linquist, B. A., Brouder, S. M., Hill, J. E., and Van-Kessel, C.: Rice yield and nitrogen utilization efficiency under alternative straw management practices, Agron. J., 92, 1096-1103, 2000.

European Commission: Forest Fires in Europe 2009, EUR 24502 EN, Office for Official Publications of the European Communities, Luxembourg, 81 pp., 2010.

Eva, H. D. and Lambin, E. F.: Fires and land-cover change in the tropics: a remote sensing analysis at the landscape scale, J. Biogeogr., 27, 765-776, 2000.

FAO: Global forest fire assessment 1990-2000, Forest Resources Assessment Programme, Working Paper No. 55, available at: http://www.fao.org/forestry/fo/fra/docs/Wp55_eng.pdf (last access: 14 April 2009), 2001.

Farina, A.: The cultural landscape as a model for the integration of ecology and economics, Bioscience, 50, 313-320, 2000.

Giglio, L., Descloitres, J., Justice, C. O., and Kaufman, Y.: An enhanced contextual fire detection algorithm for MODIS, Remote Sens. Environ., 87, 273-282, 2003.

Giglio, L., Csiszar, I., and Justice, C. O.: Global distribution and seasonality of active fires as observed with the Terra and Aqua MODIS sensors, J. Geophys. Re.-Biogeosciences, 111, G02016, doi:10.1029/2005JG000142, 2006.

Hoelzemann, J., Schultz, M. G., Brasseur, G. P., Granier, C., and Simon, M.: Global Wildland Fire Emission Model (GWEM): Evaluating the use of global area burnt satellite data, J. Geophys. Res., 109, D14S04, doi:10.1029/2003JD003666, 2004.

JRC-EEA: CORINE land cover updating for the year 2000: image 2000 and CLC2000, in: Products and Methods, edited by: Lima, V., Report EUR 21757 EN, JRC-Ispra, available at: http: //reports.eea.europa.eu/COR0-landcover/en (last access: 28 July 2011, 2005.

Jupp, T. E., Taylor, C. M., Balzter, H., and George, C. T.: A statistical model linking Siberian forest fire scars with early summer rainfall anomalies, Geophys. Res. Lett., 33, L14701, doi:10.1029/2006GL026679, 2006.

Justice, C. O., Townshend, J. R. G., Vermote, E. F., Masuoka, E., Wolfe, R. E., Saleous, N., Roy, D. P., and Morisette, J. T.: An overview of MODIS Land data processing and product status, Remote Sens. Environ., 83, 3-15, 2002.

Kamm, J. A. and Montgomery, M. L.: Reduction of insecticide activity by carbon residue produced by burning grass seed fields after harvest, J. Econ. Entomol., 83, 55-58, 1990.

Kasischke, K. S. and French, N. H. F.: Locating and estimating the aerial extent of wildfires in Alaskan boreal forests using multipleseason AVHRR NDVI composite data, Remote Sens. Environ., 51, 263-275, 1995.
Kontoes, C. C., Poilve, H., Florsch, G., Keramitsoglou, I., and Paralikidis, S.: A comparative analysis of a fixed thresholding vs. a classification tree approach for operational burn scar detection and mapping, Int. J. Appl. Earth Obs. Geoinf., 11, 299-316, 2009.

Lentile, L. Z., Holden, A., Smith, A. M. S., Falkowski, A. M. J., Hudak, A. T., Morgan, P., Lewis, S. A., Gessler, P. E., and Benson, N. C.: Remote sensing techniques to assess active fire characteristics and post-fire effects, Int. J. Wildland Fire, 15, 319-34, 2006.

Li, Z., Nadon, S., Cihlar, J., and Stocks, B.: Satellite-based detection of Canadian boreal forest fires: Evaluation and comparison of algorithms, Int. J. Remote Sens., 21, 3071-3082, 2000.

McGarigal, K. and Marks, B. J.: FRAGSTATS: spatial pattern analysis program for quantifying landscape structure, Gen. Tech. Rep. PNW-GTR-351, USDA Forest Service, Pacific Northwest Research Station, Portland, OR, 1995.

Morisette, J. T., Baret, F., and Liang, S.: Special issue on global land product validation, IEEE Trans. Geosci. Remote Sens., 44, 1695-1697, 2006.

Patra, P. K., Ishizawa, M., Maksyutov, S., Nakazawa, T., and Inoue, G.: Role of biomass burning and climate anomalies for land-atmosphere carbon fluxes based on inverse modeling of atmospheric $\mathrm{CO}_{2}$, Global Biogeochem. Cy., 19, GB3005, doi:10.1029/2004GB002258, 2005.

Petropoulos, G. P., Knorr, W., Scholze, M., Boschetti, L., and Karantounias, G.: Combining ASTER multispectral imagery analysis and support vector machines for rapid and cost-effective post-fire assessment: a case study from the Greek wildland fires of 2007, Nat. Hazards Earth Syst. Sci., 10, 305-317, doi:10.5194/nhess-10-305-2010, 2010.

Petropoulos, G. P., Kontoes, C. C., and Keramitsoglou, I.: An investigation of EO-1 Advanced Land Imager capability for land cover mapping with emphasis on Burnt Area Delineation, Int. J. Appl. Earth Obs. Geoinf., 18, 344-355, 2012.

Prasad, R., Gengaiah, B., and Aipe, K. C.: Effect of crop residue management in a rice-wheat cropping system on growth and yield of crops and on soil fertility, Exp. Agric., 35, 427-435, 1999.

Rong, R. L., Kaufman, J., Hao, W. M., Salmon, J. M., and Gao, B.-C.: A technique for detecting burn scars using MODIS data, IEEE Trans. Geosci. Remote Sens., 42, 1300-1308, 2004.

Rosa De La, J. M., Gonzalez-Perez, J. A., Gonzalez-Vazquez, R., Knicer, H., Lopez-Capel, E., Manning, D. A. C., and GonzalezVila, F. J.: Use of pyrolisis/GC-MS combined with thermal analysis to monitor $\mathrm{C}$ and $\mathrm{N}$ changes in soil organic matter from a Mediterranean fire affected forest, Catena, 74, 296-303, 2008.

Roy, D. P. and Boschetti, L.: Southern Africa Validation of the MODIS, L3JRC and GlobCarbon Burned Area Products, IEEE Trans. Geosci. Remote Sens., 47, 1032-1044, doi:10.1109/TGRS.2008.2009000, 2009.

Roy, D. P., Jin, Y., Lewis, P. E. and Justice, C. O.: Prototyping a global algorithm for systematic fire affected area mapping using MODIS time series data, Remote Sens. Environ., 97, 137-162, 2005.

Roy, P., Trigg, S. N., Bhima, R., Brockett, B., Dube, O., Frost, P., Govender, N., Landmann, T., Le Roux, J., Lepono, T., Macuacua, J., Mbow, C., Mhwandangara, K., Mosepele, B., Mutanga, O., Neo-Mahupeleng, G., Norman, M., and Virgilo, S.: The utility 
of satellite fire product accuracy information - Perspectives and recommendations from the Southern Africa fire network, IEEE Trans. Geosci. Remote Sens., 44, 1928-1930, 2006.

Roy, D. P., Boschetti, L., Justice, C. O., and Ju, J.: The Collection 5 MODIS burned area product: Global evaluation by comparison with the MODIS active fire product, Remote Sens. Environ., 112, 3690-3707, 2008.

Sedano, F., Kempeneers, P., Strobl, P., McInerney, D., and Miguel, J. S.: Increasing spatial detail of burned scar maps using IRSAWiFS data for Mediterranean Europe, Remote Sens., 4, 726744, 2012.

Sifakis, N. I., Iossifidis, C., Kontoes, C., and Keramitsoglou, I.: Wildfire detection and tracking over Greece using MSG-SEVIRI satellite data, Remote Sens., 3, 524-538, 2011.

Silva, J. M. N., Sa, A. C. L., and Pereira, J. M. C.: Comparison of burnt area estimates derived from SPOT-VEGETATION and Landsat ETM+ data in Africa: Influence of spatial pattern and vegetation type, Remote Sens. Environ., 96, 188-201, 2005.
Simon, M., Plummer, S., Fierens, F., Simon, M., Plummer, S., Fierens, F., Hoelzemann, J. J., and Arino, O.: Burnt area detection at global scale using ATSR-2: The GlobScar products and their qualification, J. Geophys. Res., 109, D14S02, doi:10.1029/2003JD003622, 2004.

Trigg, S. N. and Roy, D. P.: A focus group study of factors that promote and constrain the use of satellite derived fire products by resource managers in Southern Africa, J. Environ. Manage., 82, 95-110, 2007.

Veraverbeke, S., Verstraeten, W. W., Lhermitte, S., and Goossens, R.: Evaluating Landsat Thematic Mapper spectral indices for estimating burn severity of the 2007 Peloponnese wildfires in Greece, Int. J. Wildland Fire, 19, 558-569, 2010.

Vivchar, A.: Wildfires in Russia in 2000-2008: estimates of burnt areas using the satellite MODIS MCD45 data, Remote Sens. Lett., 2, 81-90, 2011.

Zammit, O., Descombes, X., and Zeruba, J.: Burnt area mapping using Support Vector machines, Forest Ecol. Manage., 234, S240S249, 2006. 